\title{
Survival and breeding interval of an endangered marine vertebrate, the leatherback turtle Dermochelys coriacea, in French Guiana
}

\author{
D. Chevallier ${ }^{1}$, M. Girondot ${ }^{2}$, R. Berzins ${ }^{3}$, J. Chevalier ${ }^{4}$, B. de Thoisy ${ }^{5}$, J. Fretey ${ }^{6}$, \\ L. Kelle ${ }^{7}$, J. D. Lebreton ${ }^{8, *}$ \\ ${ }^{1}$ Institut Pluridisciplinaire Hubert Curien, UMR 7178 CNRS-Unistra, 67087 Strasbourg, France \\ ${ }^{2}$ Laboratoire Écologie, Systématique, Évolution, Université Paris-Sud, AgroParisTech, CNRS, Université Paris Saclay, \\ 91405 Orsay, France \\ ${ }^{3}$ ONCFS, Campus Agronomique, 97319 Kourou CEDEX, French Guiana \\ ${ }^{4}$ Awala, 97361 Awala-Yalimapo, French Guiana \\ ${ }^{5}$ Association Kwata, 97335 Cayenne, French Guiana \\ ${ }^{6}$ UICN France, Muséum national d'Histoire naturelle, 36 rue Geoffroy Saint-Hilaire, 75005 Paris, France \\ ${ }^{7}$ WWF Guianas, French Guiana Office, 97300 Cayenne, French Guiana \\ ${ }^{8}$ Centre d'Ecologie Fonctionnelle et Evolutive, UMR 5175, CNRS Université de Montpellier, 34293 Montpellier CEDEX 5, France
}

\begin{abstract}
In the context of global change, endangered species such as sea turtles undergo strong population dynamics changes. Understanding demographic processes inducing such changes is critical for developing appropriate measures for conservation and management. Nesting females of the French Guiana population of leatherback sea turtles Dermochelys coriacea represented $40 \%$ of the world's total in 2001 ; today, they represent only $10 \%$. Here, we analyze data from the long-term monitoring program of leatherbacks in French Guiana, based on 28 yr of capture-markrecapture data from 46051 individuals in northwestern French Guiana. We used multievent models (multistate capture-recapture models with state uncertainty) to represent the main peculiarity of the life cycle, intermittent reproduction, and to take advantage of the use of several different types of marks to account for mark loss and incomplete detection. The average annual adult survival probability (mean \pm SE) $0.789 \pm 0.009$ is low compared to published estimates for this species. By combining the estimates of departure and return probabilities, we provide an estimate of the interval among laying seasons equal to $2.777 \pm 0.118 \mathrm{yr}$, which matches previous findings. Taking survival into account, this interval translates into an average of $1.704 \pm 0.034$ further reproductive seasons for an adult female having just bred, which is remarkably low compared to other longlived vertebrates. The representation of the life cycle and mark loss in our models provides a sound structure for broader and richer analyses to extract biological information from marked individuals and offers an invaluable source of demographic information on leatherbacks, a species for which only a small segment of the population is accessible to intermittent sampling.
\end{abstract}

KEY WORDS: Leatherback turtle - Dermochelys coriacea $\cdot$ Capture-mark-recapture - Mark loss · Multievent models $\cdot$ Survival $\cdot$ Reproduction $\cdot$ French Guiana

\section{INTRODUCTION}

In the current context of global change, appropriate analyses of animal population dynamics are key

\footnotetext{
${ }^{*}$ Corresponding author: jean-dominique.lebreton@cefe.cnrs.fr
}

to better understanding the relative role of natural and anthropogenic disturbance (Janzen 1994, Hallett et al. 2004). In this respect, sea turtles are of particular interest: complex physiological and behavioral

() The authors 2020. Open Access under Creative Commons by Attribution Licence. Use, distribution and reproduction are unrestricted. Authors and original publication must be credited. 
adaptations and large-scale migrations make sea turtle populations highly vulnerable to change in both marine and coastal ecosystems. Understanding how global change may affect sea turtle populations can thus provide insights into the relationship between climate, ecosystems, evolutionary processes and anthropogenic disturbance (Lovich et al. 2018). The drastic decline of many sea turtle populations pushed the international community to take steps towards conservation, including classification in Annex 1 of the Washington Convention and as Critically Endangered or Endangered (IUCN 2009, Seminoff \& Shanker 2008, The Northwest Atlantic Leatherback Working Group 2019).

The greatest threats to marine turtles are the alteration of natural habitats, climate change, overfishing, pollution and poaching, all of which contribute directly or indirectly to the species' global decline (Lutz et al. 2003). Being ectothermic, sea turtles, like most marine animals, are particularly exposed to the effects of temperature changes (Seebacher \& Franklin 2005). Various studies have indeed reported the impact of climate change on the biology, behavior and population dynamics of marine turtles. Examples include female-skewed sex ratio and changes in the pattern of reproduction and migration, which negatively affect population dynamics (McMahon \& Hays 2006, Hawkes et al. 2007, Chaloupka et al. 2008).

Understanding the demographic responses of marine turtle populations to oceanic changes is thus critical and requires a quantitative approach. In population dynamics studies, the change in emphasis from population counts to the analysis of demographic flows (Gaillard et al. 2016) reflects the general move in ecological research from pattern to process (Swihart et al. 2002). This move is particularly relevant for species with a complex life cycle, for which interpreting changes in numbers in terms of population mechanisms can be quite challenging. As a consequence, recent decades have seen the development of a number of long-term capture-mark-recapture (CMR) monitoring programs (Clutton-Brock \& Sheldon 2010) and the joint development of increasingly sophisticated statistical models to analyze the resulting data (Lebreton et al. 2009, Gimenez et al. 2012). In this context, the assessment of relationships between demographic parameters and environmental covariates, in particular those related to climate, must be based on a large number of years to be useful for population projections (Gauthier et al. 2016), enhancing the value of long-term capture-recapture programs. The leatherback turtle Dermochelys coriacea (leatherback hereafter) is particularly challenging: the females come ashore to breed only intermittently, with several clutches within a season followed by one or usually several seasons without reproduction. Monitoring individuals requires intensive field work and the use of individual marks, with a risk of mark loss and incomplete detection of individuals, which are common issues in animal CMR programs. Both phenomena, if not appropriately accounted for, tend to result in an underestimation of survival. Moreover, permanent emigration, even more difficult to account for, in particular with the potential presence of transient individuals only coming ashore to the study site for 1 season, tends to induce an underestimation of survival. These impediments are responsible for the limited demographic information available despite the crucial need for more data on this endangered species (Sarti Martinez 2000, Seminoff 2004).

French Guiana beaches represent an important nesting site for leatherbacks (Girondot \& Fretey 1996, Fretey \& Lescure 1998). Turtles come to nest on sandy beaches and require mud-free habitat during the oviposition phases (Carr \& Carr 1972, Kelle et al. 2007). While the French Guiana population of leatherbacks represented $40 \%$ of the world's leatherbacks in 2001, today it represents $10 \%$, with 1500 annual nests in 2013 vs. 18000 in 2001, equating to an average decline of $19 \% \mathrm{yr}^{-1}$. This strong decline is consistent with declines at a broader scale: for the 19902018 period, the numbers of nests declined at a rate of $5.04 \% \mathrm{yr}^{-1}$ for Guianas-Trinidad and $4.21 \% \mathrm{yr}^{-1}$ for the whole western Atlantic-Caribbean region (Wallace 2019).

A long-term marking program in French Guiana, initiated in the 1980s, has provided valuable insights into leatherback demography (Rivalan et al. 2006a), population genetics (Rivalan 2006b, Molfetti et al. 2013) and behavioral ecology at sea (Ferraroli et al. 2004, Fossette et al. 2008, Chambault et al. 2017).

Here, we analyze data obtained in northwestern French Guiana within this long-term program, based on CMR data of 46051 individuals over $28 \mathrm{yr}$. We use recent multistate capture-recapture models with uncertainty on state (multievent models, Pradel 2005, Gimenez et al. 2012) to efficiently represent the main peculiarity of the life cycle, intermittent reproduction, and to take advantage of the use in this program of several different types of marks to efficiently account for mark loss and incomplete detection. We expect to link the strong population decline and the estimates of demographic parameters such as adult survival probability and inter-nesting period (number of years between 2 nesting seasons or remigration interval) over the $28 \mathrm{yr}$ of the study. Our analysis 
will provide a basis for future work to explain demographic variation and evaluate the potential of the populations to respond to changing environments in the context of global change.

\section{MATERIALS AND METHODS}

\subsection{Materials and field methods}

This study took place at Awala-Yalimapo beach, French Guiana $\left(5^{\circ} 42^{\prime} 47^{\prime \prime} \mathrm{N}, 53^{\circ} 47^{\prime} 9^{\prime \prime} \mathrm{W}\right)$, located on the eastern side of the Maroni River estuary (Fig. 1).

During the study period, Awala-Yalimapo beach was the beach with the greatest number and density of nests in the region (Spotila et al. 1996). However, nearby beaches also host nesting leatherbacks, especially in Suriname on the western side of the Maroni River (e.g. Baboensanti, Kolukubo beaches). Because observations show that some females nest on both sides of the Maroni River (Hilterman \& Goverse 2007), females from western French Guiana and eastern Suriname are thought to belong to the same subpopulation. Monitoring of Suriname breeding sites has been intermittent and irregular, with some intensive monitoring from 2001 to 2004, but we had no access to the data obtained in Suriname. We discuss later (Section 4.2) the potential consequences on demographic estimates of movements of individuals between the 2 sides of the Maroni River.

In our study site, since 1978, individual identification of breeding females by CMR has been performed using several types of markers. From 1978 to 1983, plastic Rototags were used, and from 1983 to 1986, these were replaced by numbered titanium tags, all on the left front flipper. From 1987 to 1994 and in 1997, females were tagged with a self-piercing numbered Monel metal tag on the left rear flipper (Girondot \& Fretey 1996). From 1994 onwards, 2 Monel metal tags were applied to nesting females, attached at the rear left and right flippers. From 1995 to 2013 (1997 excluded), tagging was performed by injecting a passive integrated transponder (PIT) into the neck (Rivalan et al. 2006b) or right shoulder muscles of nesting females. Each year from 1985 to 1999, from March-April to mid-August, the beach was patrolled at night from $2 \mathrm{~h}$ before until $2 \mathrm{~h}$ after the high tide, typically leading to monitoring approximately $80 \%$ of the females nesting during the night (Girondot \& Fretey 1996). Nesting females encountered during patrols were scanned for tags. If a tag was present, its identity was recorded. If no tag was present, the female was tagged. From 2000 to 2013,
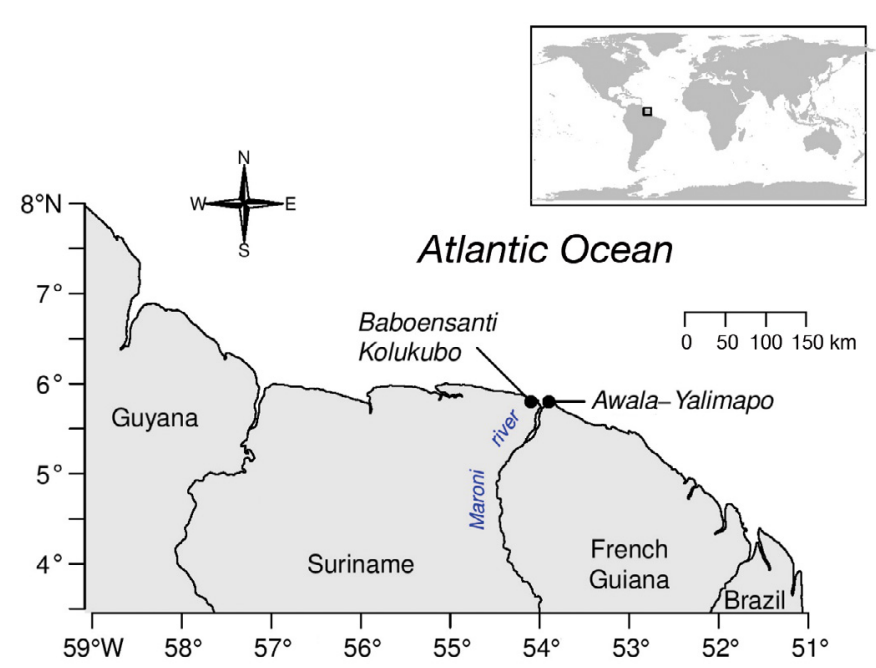

Fig. 1. Study area of Awala-Yalimapo, near the mouth of the Maroni River, border between French Guiana and Suriname

CMR monitoring of leatherback populations was performed regularly from February to July. The nocturnal patrols were conducted by a team of 4 to 6 people, from 18:00 to $08: 00 \mathrm{~h}, 4 \mathrm{~h}$ before and after the high tide, on the $3 \mathrm{~km}$ stretch of Awala-Yalimapo beach (Amana Nature Reserve). Each observed female was scanned to identify PIT or metal tags, and some morphometric measurements were taken. If the individual was not tagged, a PIT was inserted in the left shoulder. Throughout the nesting periods, observers systematically recorded the GPS location of the animal, time, PIT and/or metal tag number and beach location (sand, bank, vegetation or water) for each individual.

Our CMR analysis covered $28 \mathrm{yr}$, from 1986 to 2013, with data prior to 1986 and for most of 1989 not being available. For the current analysis focusing on inter-season dynamics, the data were organized on a yearly basis, with all captures of the same individual within a season being lumped as a single capture event.

\subsection{CMR analysis}

The models considered are based on a series of states among which each individual moves, and events characterizing what is recorded. The information recorded in the events may, however, not provide full information on the underlying state of a recaptured individual at the particular time considered, and this is accounted for in the modeling. Therefore, an appropriate description of the correspondence between states and events is crucial. Movement among states 
only depends on the current state, i.e. transition among states constitutes a Markov chain. As the information on states is not exhaustive, such models are called hidden Markov chains. Gimenez et al. (2012) provide a full presentation of CMR models based on hidden Markov chains.

The states among which marked individuals could move from one year to the next were a combination of biological states: dead vs. alive, and among those alive, present (i.e. coming ashore in the current season to lay eggs, abbreviated as PRE) or absent (abbreviated as ABS), and the type of marks. Individuals could be marked with 1 or several metal (M) tags, 1 or several PIT (P) tags or both types of tags (MP). Because of heterogeneity and incomplete information in the field records, we did not attempt to consider the number of metal and/or PIT tags, just the presence of these 2 types of marks. The potential heterogeneity of recapture probability among individuals induced by this approximation is accounted for through an overdispersion coefficient. The 7 resulting states were, thus, in straightforward notation: DEAD, PRE-M, PRE-P, PRE-MP, ABS-M, ABS-P, ABS-MP.

We modeled the transitions among states from one year to the next in a way that allowed not only for death/ survival and presence/absence but also for loss of marks. To adequately represent these different types of transitions, the Markovian transition from one year to the next was split into 4 successive phases (Fig. 2), each represented by a transition submatrix: survival (submatrix S), retention or loss of metal mark(s) (submatrix LM), retention or loss of PIT tag(s) (submatrix LP) and movement (i.e. transition from PRE to ABS and from ABS to PRE) (submatrix $\mathbf{M}$ ). Throughout, matrices are denoted with starting states as rows and arrival states as columns. Because the states are a set of mutually exclusive alternatives, all matrices are row stochastic, i.e. the sum of their rows are all equal to 1 , and time runs from left to right in the matrix products. Thus, the overall transition matrix among the 7 states was $\mathbf{T}=\mathbf{S} \times \mathbf{L M} \times \mathbf{L P} \times \mathbf{M}$. The 4 steps in the transitions and their parameterizations are described in a qualitative fashion below, and the cor-
Survival Retention/Loss Retention/Loss Movement of metal tag of PIT tag

(n)

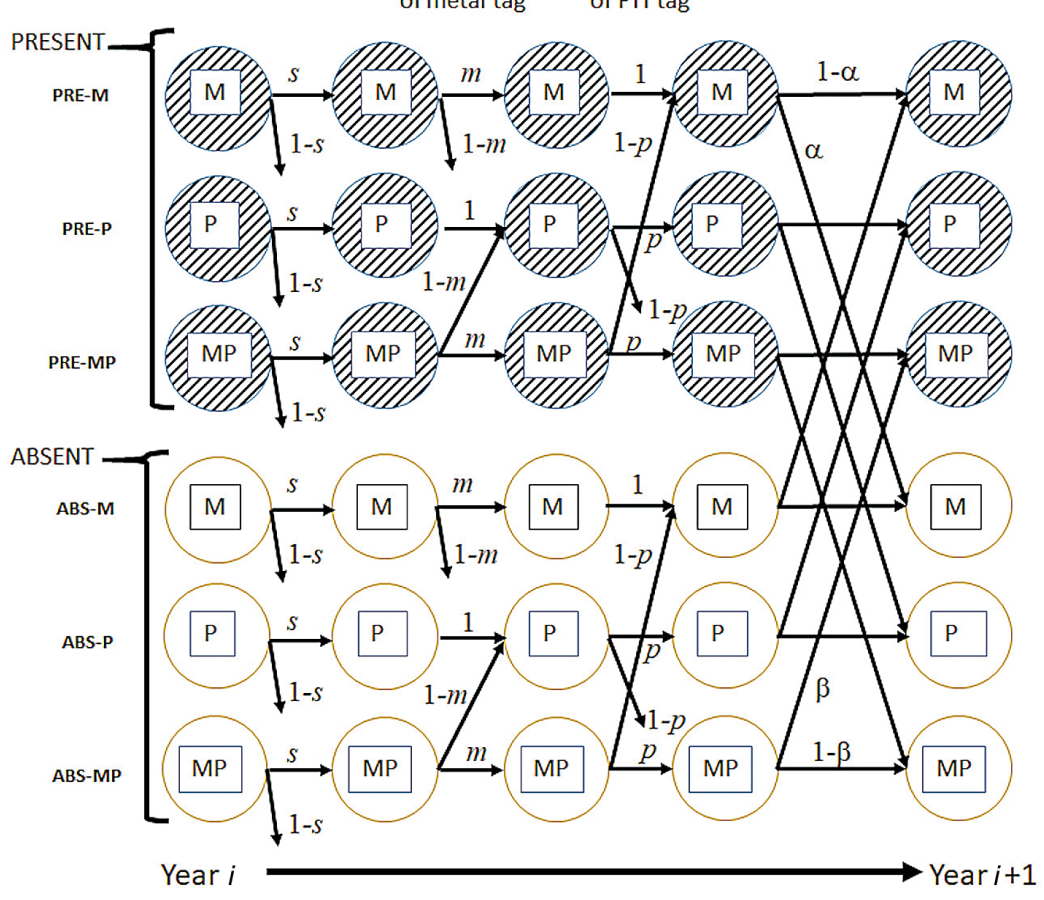

Fig. 2. Flow chart of transitions among states from one year to the next in the . o 6 states for individuals alive and marked: PRE-M, PRE-P, PRE-MP, ABS-M, of the 6 alive states. The year-to-year transitions are thus based on five types parameters: (1) probability of survival, $s_{i}(2)$ probability of metal tag retenfor an i (3) probability of PIT tag retention, $p_{i}(4)$ probability of being absent probability of being present for an individual absent in the current year (probability of return), $\beta$

responding matrices are given in the Supplement at www.int-res.com/articles/suppl/n041p153_supp.pdf.

The annual survival probability was considered not to vary with the marks $(\mathrm{M}, \mathrm{P}$ or $\mathrm{M}+\mathrm{P})$. As usual, in models with temporary emigration to unobservable states (here, the 3 ABS states), we assumed the survival probability did not vary with the presence status (Kendall et al. 1997). This restrictive assumption cannot be avoided given the life cycle of the species. Therefore, the survival probability was uniform for a given year among the 6 states PRE-M, PRE-P, PREMP, ABS-M, ABS-P and ABS-MP.

We classified the addition of a new type of tag (e.g. adding a PIT tag to an individual with a metal tag) as follows. The capture history of an individual receiving a new tag type in year $i$ was split into 2 parts: (1) from year 1 to year $i$, time at which the individual was considered as removed from the sam- 
ple with its previous tag type; and (2) from year $i$ to the last year, with a release in year $i$ with the new tag combination.

We considered the risk of metal tag loss and the risk of PIT tag loss as independent by treating them as successive steps. This assumption of independent risks of loss is logical for marks as different as metal and PIT tags but would not be tenable for the same type of mark (Rivalan et al. 2005a). One should note that the loss of a PIT tag may mean permanent loss of detectability, e.g. by migration of the tag under the surface of the body, and does not necessarily imply the mark dropped from the individual. Retention or loss of metal tags from one year to the next generated non-null transition probabilities from $\mathrm{M}$ to DEAD, and MP to $\mathrm{P}$ with probability $1-m$, based on a retention probability $m$. Similarly, the retention/loss of PIT tags was based a retention probability $p$. As we assumed the 2 types of losses were independent, their order in the sequence of transitions did not matter. In these steps, the transition to DEAD accounted for permanent loss of marked individuals because they become unmarked. We assumed the same probability $1-m$ for the transitions MP to $\mathrm{P}$ and $\mathrm{M}$ to DEAD and, similarly, $1-p$ for the transitions MP to $\mathrm{M}$ and $\mathrm{P}$ to DEAD. These assumptions about mark loss made it possible to estimate $m$ and $p$ separately from survival $s$, thus correcting the estimation of survival for mark loss. Movement was considered as not depending on the type of marks. It was characterized by 2 parameters: a departure probability $\alpha$, which is the probability that a survivor will be absent the following year (i.e. will not come ashore to lay eggs), and a return probability $\beta$, which is the probability that an individual absent and surviving will come back to lay eggs the following year.

The split into 4 successive phases made it possible to represent complex transitions in a straightforward way (Fig. 2, and overall transition matrix $\mathbf{T}=\mathbf{S} \times \mathbf{L M}$ $\times \mathbf{L P} \times \mathbf{M}$ in the Supplement).

In a given recapture season, individuals dead or absent, i.e. in 1 of the 3 ABS states, had a detection probability of 0 , an event denoted as $U$ for unrecorded. Each season an individual was detected, it was necessarily present, i.e. in 1 of the 3 PRE states (PREM, PRE-P or PRE-MP) and recorded with metal and/or PIT tag(s). However, not all marks present were recorded uniformly (in particular for field sessions done without a PIT tag reader). As a consequence, an individual with metal and PIT tags (state PRE-MP) could be unrecorded or recorded with a metal tag only, PIT tag only or both (events denoted as $\mathrm{U}, \mathrm{M}, \mathrm{P}$ or $\mathrm{MP}$, respectively). The relationship between the 4 events $\mathrm{U}, \mathrm{M}, \mathrm{P}$ and $\mathrm{MP}$ and the 7 underlying states was thus necessarily probabilistic, expressed by a matrix of detection probabilities:

\begin{tabular}{lcccc} 
& $\mathrm{U}$ & $\mathrm{M}$ & $\mathrm{P}$ & $\mathrm{MP}$ \\
\hline DEAD & 1 & 0 & 0 & 0 \\
PRE-M & $1-\mathrm{g}$ & $\mathrm{g}$ & 0 & 0 \\
PRE-P & $1-\mathrm{h}$ & 0 & $\mathrm{~h}$ & 0 \\
PRE-MP & $1-\mathrm{j}-\mathrm{k}-\mathrm{l}$ & $\mathrm{j}$ & $\mathrm{k}$ & $\mathrm{l}$ \\
ABS-M & 1 & 0 & 0 & 0 \\
ABS-P & 1 & 0 & 0 & 0 \\
ABS-MP & 1 & 0 & 0 & 0
\end{tabular}

By considering that the detection of a metal tag and a PIT tag were independent, the 5 types of detection parameters in the matrix above were reduced to 2 , both varying over time because of different monitoring effort over the years.

Besides these detection probabilities (which concern only recaptures and thus do not exist for the first study year), the parameters also include probabilities that the females captured for the first time each year and marked (in 1 of the 3 states PRE-M, PRE-P and PRE-MP) are in 1 of these 3 states, depending on the type of marks they receive. These parameters reflected only the distribution of the various types of tags used each year and were necessarily time dependent. Each year, the 3 probabilities of being at initial capture in states M, P or MP add up to 1 and are redundant. Therefore, only 2 of these 3 parameters were needed for each of the $28 \mathrm{yr}$ of capture. The resulting 56 parameters do not bring any useful information and are not further displayed or discussed.

The transition parameters were thus of 5 types $(s$, $m, p, \alpha, \beta)$. These 5 parameter types were considered as constant, or varying according to various effects such as time, based on the classical philosophy of modern CMR models (Lebreton et al. 1992). The probabilities of survival $s$ and movement $\alpha$ and $\beta$ were considered as either constant or time dependent. Considering any more complex effects (such as time since last presence or effect of presence/ absence) induced pervasive identifiability problems, preventing us from separately estimating these parameters. For the probabilities of tag retention $m$ and $p$, constancy or variation over time were combined in various fashion with the age of the tag, i.e. with time since initial marking, coded with 2 levels: first year after marking, and the following years. For survival, the same type of age effect was considered to account for transience (Pradel et al. 1997). 
In the absence of exact goodness-of-fit tests for multievent models, the quality of fit of the most general model was tested in an approximate fashion using the multistate goodness-offit test in the program U-CARE (Choquet et al. 2009a). The estimated overdispersion $\hat{c}$ coefficient derived from these tests was biased upwards by incorporating part of the variability induced by the probabilistic relationship between states and events. Models under different assumptions on the parameters (time dependence, age dependence, constancy) were fitted using the program E-SURGE (Choquet et al. 2009b), of which 2 key characteristics in our case make it possible to split transitions in several phases as a matrix product and efficiently represent the probabilistic relationship linking states and events. Information on the model structure and E-SURGE implementation is given in the Supplement. We ran each model at least 10 times with random initial values to ensure convergence to the global minimum of the deviance (Lebreton et al. 2009). Model selection, based on the deviance dev and the number of identifiable parameters $n p$ provided by E-SURGE for each model, was classically based on QAIC $=d e v / \hat{c}+2 n p$ (Lebreton et al. 1992). Because of the upward bias of the estimated coefficient of overdispersion, model selection was thus conservative, i.e. favored parsimonious models (Lebreton et al. 2003). A difference of QAIC greater than 2 is generally considered as significant. In the case of doubt about parameter identifiability, the identifiability in the final model of some parameters was investigated by running the model (10 times again) with a fixed arbitrary value for the focal parameter and checking the resulting difference from the final model in deviance and estimates.

We derived estimates of compound demographic parameters of interest (see the Supplement). Denoting as $S, D$ and $R$, the probabilities of survival, departure and return, respectively, the inter-nesting interval for a surviving individual was obtained as $1+D / R$ and the probability of a further reproductive event as $(1-D) S+D R S^{2} /(1-(1-R) S)$. The SEs of these derived quantities were obtained by the delta method.

\section{RESULTS}

The goodness-of-fit tests resulted in an estimated $\hat{c}=3.5852$. This fairly high value, conservative with respect to model selection, resulted from the approximation of the goodness-of-fit tests for multievent
Table 1. Capture-mark-recapture models with different effects for the probabilities of mark retention, under time dependence for survival, departure and return probabilities. The models are ranked by ascending QAIC value (i.e. with preferred model in the first row). Effects are as follows: time = variation over time; age = age of mark, with 2 levels, first year after initial marking vs. following years; age.time $=$ independent variation over time in first year after marking and afterwards; age + time = parallel variation (on a logit scale) over time in first year after marking and afterwards. PIT: passive integrated transponder

\begin{tabular}{|lcccc|}
\hline $\begin{array}{l}\text { Retention } \\
\text { of PIT tag }\end{array}$ & $\begin{array}{c}\text { Retention } \\
\text { of metal tag }\end{array}$ & Deviance & $\begin{array}{c}\text { No. of } \\
\text { identifiable } \\
\text { parameters }\end{array}$ & QAIC \\
\hline Age + Time & Age & 112491.72 & 196 & 31768.69 \\
Age + Time & Age + Time & 112408.70 & 218 & 31789.54 \\
Age.Time & Age & 112487.81 & 211 & 31797.60 \\
Age & Age & 112731.34 & 179 & 31801.53 \\
Age + Time & Age.Time & 112384.06 & 233 & 31812.66 \\
Age.Time & Age + Time & 112403.97 & 233 & 31818.22 \\
Age & Constant & 112806.63 & 178 & 31820.53 \\
Age & Age + Time & 112645.04 & 201 & 31821.46 \\
Age.Time & Age.Time & 112380.16 & 248 & 31841.58 \\
Age & Age.Time & 112620.59 & 216 & 31844.64 \\
Constant & Age & 112998.94 & 178 & 31871.10 \\
Constant & Constant & 113063.88 & 177 & 31890.28 \\
Time & Time & 113011.69 & 209 & 31939.77 \\
\hline
\end{tabular}

models and the heterogeneity in the data. This heterogeneity may result in particular from differences in detection probabilities among individuals potentially caused by (1) simply noting, at the coding stage, the presence of each type of mark (metal or PIT tags), not their number, (2) the reduction of several recaptures within a season to a single event and (3) genuine differences among females in the number of visits to the breeding site within a season.

We first examined the structure of the parameters for mark retention/loss $m$ and $p$, assuming survival $\mathrm{s}$, probability of departure $\alpha$ and probability of return $\beta$ were simultaneously time dependent, to avoid bias in the analysis of mark retention (Table 1). In this first step, models with effects of the age of marks (either metal tag or PIT) were preferred to models without such effects by more than 2 points of QAIC, providing at this stage some evidence for differential rates of loss in the first year after marking and in the following years for both types of marks. The preferred model had an age effect of the metal tag and of the PIT with an additive effect of time for the latter, which may reflect variation in the PIT tag injection locations in the body over time.

Then, variations in the 3 key demographic parameters (probabilities of survival $s$, departure $\alpha$ and return $\beta$ ) were examined under the preferred structure for mark loss/retention obtained in Table 1. The 
Table 2. Capture-mark-recapture models with different effects for the probabilities of mark retention, under time dependence and effect of time since marking (age, with 2 levels, first year after marking and following years) for survival, and time dependence in departure and return probabilities. The models are ranked by ascending QAIC value (i.e. with preferred model in the first row). Effects are as follows: constant $=$ constancy, with resulting single parameter possibly fixed to 1 ; time $=$ variation over time; age = age of mark, with 2 levels, first year after initial marking vs. following years; age + time = parallel variation (on a logit scale) over time in first year after marking and afterwards. PIT: passive integrated transponder

\begin{tabular}{|lcccccc|}
\hline Survival & $\begin{array}{c}\text { PIT } \\
\text { retention } \\
\text { probability }\end{array}$ & $\begin{array}{c}\text { Metal tag } \\
\text { retention } \\
\text { probability }\end{array}$ & Deviance & $\begin{array}{c}\text { No. of } \\
\text { identifiable } \\
\text { parameters }\end{array}$ & QAIC & $\begin{array}{c}\Delta \text { QAIC } \\
\text { (difference in QAIC } \\
\text { from preferred model) }\end{array}$ \\
\hline Age + Time & Constant & Age & 112494.93 & 180 & 31737.59 & 0.00 \\
Age + Time & Constant & Constant & 112496.26 & 179 & 31735.96 & 1.63 \\
Age + Time & Constant $=1$ & Constant & 112523.43 & 178 & 31741.54 & 3.95 \\
Age + Time & Age + Time & Age & 112428.74 & 198 & 31755.58 & 17.99 \\
Time & Age + Time & Age & 112491.72 & 196 & 31768.69 & 31.10 \\
Age + Time & Constant & Constant $=1$ & 112748.82 & 178 & 31804.41 & 66.82 \\
Age + Time & Constant $=1$ & Constant $=1$ & 112769.39 & 177 & 31808.14 & 70.55 \\
\hline
\end{tabular}

models with constancy in $s, \alpha$ or $\beta$ had a QAIC larger by 234, 669 and 73, respectively, than the models with time dependence, demonstrating highly significant variation over time in the probabilities of survival, departure and return.

We then examined transience in survival by considering different survival probabilities in the first year after marking and in the following years (age of mark coded with 2 levels), with an additive effect of age and time in survival (Table 2). Such models were systematically preferable to models with only time dependence in survival. The age effects in tag retention probabilities were no longer needed, but the retention probabilities, whether of metal tags or PIT tags, could not be made equal to 1, i.e. mark loss was significant for both types of marks.

Thus, the preferred model was characterized by (1) additive effects of time and age of the mark on survival probability; (2) constant retention probabilities for metal and PIT tags, differing with tag type; and (3) time-dependent departure and return probability.

As usual in models considering transience by using an effect of the age of marks (Pradel et al. 1997), the survival probability of non-transient individuals was obtained as the probability of survival $1 \mathrm{yr}$ after marking and for the following years. There were thus simultaneous pieces of evidence for transience, metal tag loss and PIT tag loss.

The estimated annual probability of the retention of metal tags was 0.898 (95\% CI: $0.865-0.992)$. The estimated annual probability of the retention of PIT tags was 0.991 (95\% CI: 0.962-0.998) but could not be set equal to 1 . The estimable probabilities of survival, displayed over time in Fig. 3, had an average value equal to $0.789 \pm 0.009$ (95\% CI: $0.771-0.806)$. Over the first $12 \mathrm{yr}$, when metal tags were the dominant type of marks and the dataset contained fewer individual encounter histories, the estimates show a great deal of variation. A large part of this variation is attributable to sampling variation, as shown by some large sampling SEs, and ups and downs resulting from the negative sampling correlation between successive estimates inherent in CMR estimation of survival.

The variance of the estimates of survival (0.0132) is the sum of a sampling variance (equal to 0.0014 ) and

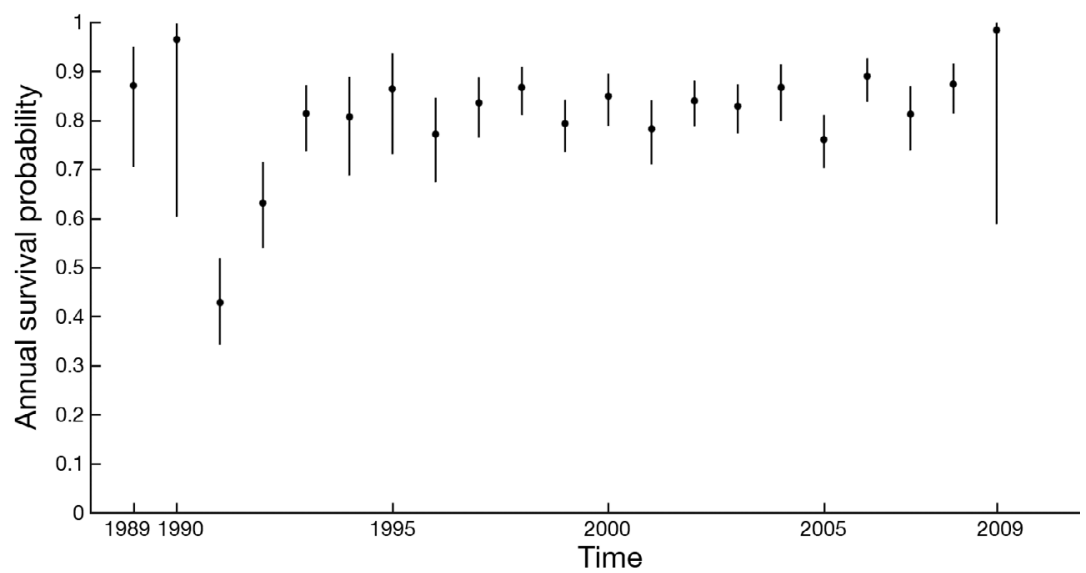

Fig. 3. Estimated annual probability of survival over time of female leatherback turtles breeding in French Guiana from 1989-1990 to 2009-2010 (labelled as 1989 and 2009, respectively). Survival estimates for other annual intervals (1986-1989 and 2009-2013) are not separately estimable from other parameters in the capture-recapture model. Vertical lines give the $95 \%$ CI of each estimate 


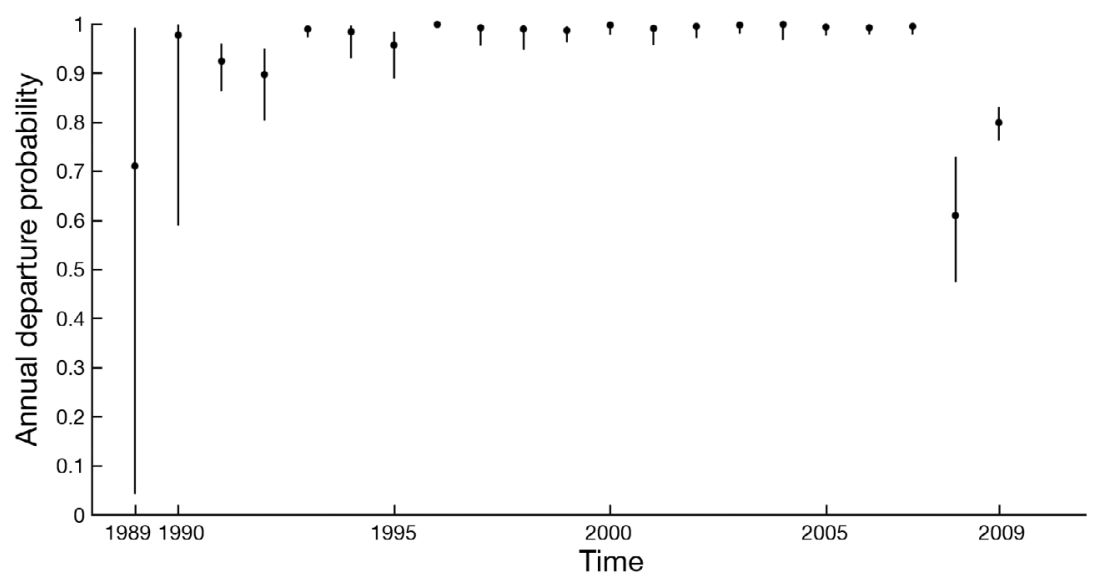

Fig. 4. Same as Fig. 3, except for estimated annual probability of departure over time. Asymptotic CIs cannot be obtained for estimates equal to 1

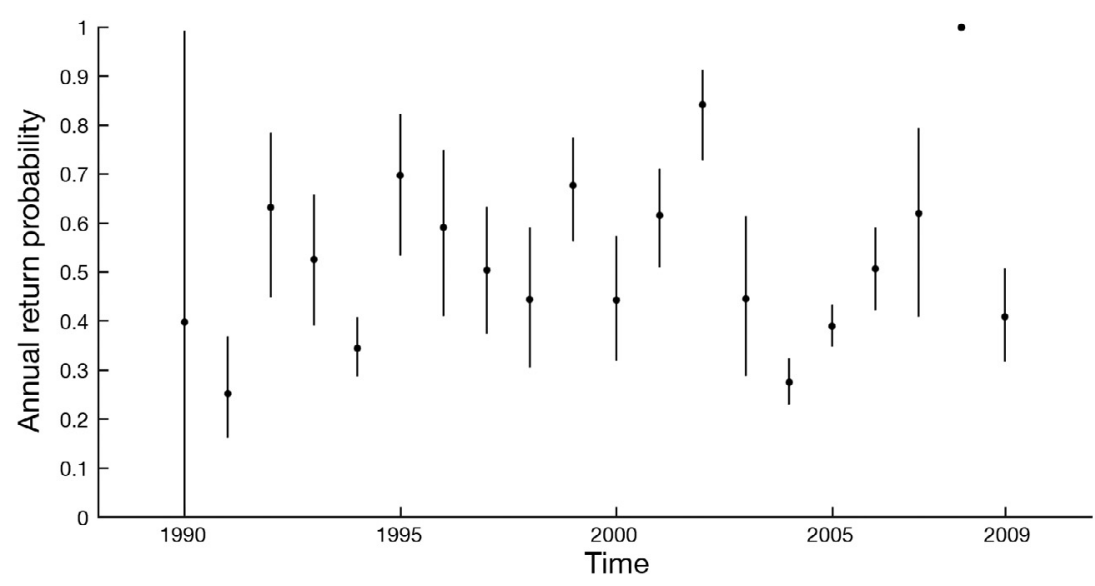

Fig. 5. Same as Fig. 3, except for estimated annual probability of return over time. Asymptotic CIs cannot be obtained for estimates equal to 1

a process variance resulting from environmental variation over the years (Gould \& Nichols 1998). The process variance was then estimated as 0.0132 $-0.0014=0.0118$. Therefore, the annual survival probability can be viewed as varying over the years as a random variable with mean 0.789 and SE 0.109 $(=\sqrt{ } 0.0118)$.

Figs. 4 \& 5 give the estimated probabilities of departure and return, when estimable. Despite wide CIs, there is genuine and marked variation over time, as shown by model selection, for departure as well as for return probability. The mean \pm SE probabilities of departure and return were $0.942 \pm 0.020$ and $0.530 \pm$ 0.032, respectively.

Based on the estimated averages of departure and return probabilities $(0.789 \pm 0.009,0.942 \pm 0.020$ and $0.530 \pm 0.032)$, the estimated average interval between 2 successive laying seasons for a survivor was $2.777 \pm 0.118$ yr (95\% CI: 2.547-3.008).
Furthermore, the probability of having one more season of reproduction for a leatherback that just laid eggs was equal to $0.587 \pm 0.012$. The number of further reproductive seasons in the life of a female leatherback was thus the expectation of a geometric distribution with rate 0.587 , i.e. 1.704 \pm 0.035 .

Over the years for which the survival and movement probabilities were identifiable, the average detection probability of a metal tag was 0.625 (1997-2011) and that of a PIT tag 0.719 (1997-2011, as the systematic use of PIT tags started in 1996). While the probability of detection of metal tags was higher than that of PIT tags in 5 of the 8 yr from 1997 to 2004, it was systematically lower for the 7 following years (2005-2011), emphasizing the increasingly systematic use of PIT detection devices over time.

The average survival estimate in the preferred model without transience (lowest QAIC model in Table 1) (0.788) does not differ from the estimate (0.789) in the preferred final model with transience (lowest QAIC model in Table 2), although the latter is 33.3 units of QAIC ahead of the former, with as a counterpart, very different estimates of probabilities of tag loss.

\section{DISCUSSION}

The CMR-based approach we used in this study encapsulated the prominent features of the biology and of the mark-recapture sampling procedures and made it possible to model demographic parameters for adult female leatherbacks over 28 yr despite unavoidable data gaps in nesting information. In particular, our approach benefited from the historical use of external metal tags and of more recent PIT tag marking to assess and account for mark loss and thus protect estimates of survival from underestimation. Our CMR analysis provides evidence for transience, i.e. an excess of individuals disappearing immediately after marking. We therefore first discuss tag loss and transience and then the estimates of the demographic parameters of interest. 


\subsection{Mark loss and transience}

Based on individuals with several metal tags in the early years of the same monitoring program, Rivalan et al. (2005a) provided evidence of a high loss rate immediately after marking, translating into an annual probability of retention equal to 0.75 in the first year, increasing afterwards. Our estimate of the annual probability of retention in the final model (with transience) (0.898) is higher and independent of the time since marking. However, in the preferred model without transience, the estimated probability of retention is 0.702 in the first year after marking and 0.947 afterwards, matching closely Rivalan et al.'s (2005a) results. Similarly, the high retention rate of PIT tags in our final model (0.991) drops considerably in the best model without transience $(0.767$ in the first year after marking, 1.000 afterwards). As discussed by Rivalan et al. (2005a) for metal tags and by Gibbons \& Andrews (2004) and Pfaller et al. (2019) for PIT tags, there is often a greater initial rate of tag loss resulting from incorrect manipulations. Gibbons \& Andrews (2004) also mention migration of the tag within the body, documented in many animals, including sea turtles. Therefore, one may question the $1 \%$ of PIT tag failures estimated in our final model and the absence of a first year effect on the rate of metal tag retention. One may thus conclude that our final model probably underestimates tag loss. As tag loss and transience are both represented as the effects of time since marking (age) on tag loss and survival, respectively, there are some unavoidable trade-offs between the 2 types of effects. Therefore, our final model probably overestimates transience by incorporating some tag loss effect in the additive effect of time since marking on survival. However, the preferred models with and without transience provide similar estimates of average annual survival (0.789 and 0.788 , respectively).

\subsection{Demographic parameters}

The meta-analysis of sea turtle survival by Pfaller et al. (2018) gathers all published estimates of survival of adult female leatherbacks and provides a sound basis for discussing survival.

We compare first our average estimated survival $(0.789 \pm 0.009)$ with previous analyses based on the same monitoring program, using part of the data we used.

Rivalan et al. (2008) summarize the use of a multistate CMR model with unobservable states to account for absence and an unexplained correction for mark loss but do not provide goodness-of-fit tests, resulting in overoptimistic CIs. Their annual survival estimate for metal (Monel) tags for 1988 to 1995 is equal to 0.70 (95\% CI: 0.45-0.96). The mean estimate for the same period from our analysis, 0.752, excluding 1988 and 1989 for which survival probabilities were not separately estimable, is similar. Their survival estimate for PIT tag data only, 1995 to 2003 (0.97, 95\% CI: 0.92-0.99), is much higher than the mean of our estimates for the same period (0.8236), despite our careful correction for mark loss and transience. In the absence of goodness-of-fit tests, their CI is overoptimistic, which explains part of the discrepancy. Their unusually high survival estimate might also result from convergence of the deviance minimization algorithm to a local minimum, producing erroneous maximum likelihood estimates. This risk is inherent to multistate and multievent CMR analyses (Lebreton et al. 2009, p 115) and may be prevented by running each model-fitting procedure at least 10 times, as we did, to ensure convergence of the deviance minimization to a global minimum.

Rivalan et al. (2005b) provide a much more detailed account of a multistate model for individuals marked with PIT tags for 1995 to 2002. They used a 2 age class effect on survival, attributed to transience of individuals, but which necessarily includes a correction for mark loss. They corrected for lack of fit using an overdispersion coefficient close to ours (3.47 vs. 3.59). Their mean survival (0.91, CI: 0.75-0.97) compares favorably to our average survival estimate for this period (0.824) once the wide $\mathrm{CI}$ of the former is taken into account. As Rivalan et al. (2005b) consider the probability of return after $3 \mathrm{yr}$ is 1, their estimated probabilities of departure and return are biased by this truncation and cannot be easily compared with ours.

Among other studies, Pilcher \& Chaloupka (2013), using data from New Guinea on 178 individuals, used 2 age classes for survival (without interpreting it as the effect of mark loss), with a resulting survival estimate equal to 0.85 (95\% CI: 0.66-0.95), constant over the years. The $95 \%$ CI seems overly optimistic given the size of the data set, presumably because of underestimation of the variance inflation factor. The probability of absence after a breeding season (0.94) is similar to our estimate (0.942).

Dutton et al. (2005) analyzed data from the Virgin Islands on 483 individuals, in a population growing at ca. $13 \% \mathrm{yr}^{-1}$. Their survival estimate $(0.893,95 \% \mathrm{CI}$ : $0.87-0.92)$ is higher than ours $(0.789 \pm 0.009)$. A high survival estimate (0.889) was also produced for a 
Florida population increasing at $10 \% \mathrm{yr}^{-1}$ by Stewart et al. (2014).

Thorson et al. (2012), using a large data set from 1965 to 2009 in South Africa, corrected for metal mark loss, based on a subsample of individuals also having a PIT tag and assuming no loss of a PIT tag. Pfaller et al. (2018, their Fig. 1) report for this study an average survival estimate equal to 0.82 (95\% CI: 0.74-0.88). Thorson et al.'s (2012) model is indeed a multistate model with unobservable states. The absence of correction for PIT tag loss may explain the fairly low survival estimate. The other estimates reported by Pfaller et al. (2018) (Spotila et al. 2000, Tomillo 2007) are based on enumeration rather than CMR analysis and are, not surprisingly, quite low with wide CIs.

Indeed, none of these studies passes the tests of considering simultaneously (1) appropriate model structure, (2) correction for tag loss and transience, (3) appropriate variance inflation factor and in turn unbiased CIs and (4) protection against local minima of the deviance in iterative maximum likelihood estimation.

For these reasons, published estimates are biased low, reinforcing the fact that our estimate of survival is in the low part of the range of published estimates. Several potential reasons have to be discussed.

First, a slight downward bias in our estimate might be attributed to heterogeneity of capture among individuals, partly corrected in some of the studies cited by the use of the so-called robust design (although the statistical analyses do not always get full advantage from this design for handling heterogeneity of capture). However, given the high probabilities of recapture in our study, this downward bias is likely to be negligible (Fletcher et al. 2012).

Second, as always in CMR of individuals alive, the survival probability incorporates some permanent emigration, i.e. is an apparent survival probability. Our final model takes permanent emigration in the year after marking (transience) fully into account. In short data sets, long-term temporary emigration may appear as permanent at the time scale considered and thus can be confounded with survival. The temporal length of our data set and the elimination of non-estimable parameters for the last sampling years make this risk of bias negligible in our case. The general decrease in numbers reported by Wallace (2019) for the period 1990 to $2018\left(-12.95 \% \mathrm{yr}^{-1}\right.$ for Yalimapo, $-5.04 \% \mathrm{yr}^{-1}$ for Guianas-Trinidad and $-4.21 \%$ $\mathrm{yr}^{-1}$ for the whole western Atlantic-Caribbean region) suggests that survival was low throughout the region and that dispersal between sites could not be the main driver of local decreases. As the decrease at Yalimapo has been stronger than that at the regional scale, our survival estimate may indeed reflect some permanent emigration to neighboring sites. However, the pieces of information available from Suriname bring moderate support to the hypothesis of a strong permanent emigration to these neighboring laying sites: (1) nest counts in Suriname showed a decline from 1998 to present at a pace of $5.14 \% \mathrm{yr}^{-1}$ (Wallace 2019); (2) no large breeding sites were discovered in Suriname during an aerial survey in 1997 after the decline at Yalimapo had started (Chevalier et al. 1998); and (3) the proportion of leatherbacks captured with a non-Surinamese PIT tag remained relatively stable over the period 1999 to 2005 (Hilterman \& Goverse 2007), although this was the period of rapid development of PIT tag marking in Yalimapo.

We thus conclude that the annual adult survival probability in our study population is genuinely low. This conclusion raises the issue of anthropogenic impacts at sea, as $25 \%$ of individuals have marks indicative of wounds from nets or hooks (Chevallier unpubl. data).

By combining the estimates of average departure and return probabilities, we obtained an estimate of the interval among laying seasons, commonly called remigration interval, equal to $2.777 \pm 0.118 \mathrm{yr}$ (CI: 2.547-3.008). As for most such estimates, it could be overestimated because of some temporary emigration to lay eggs in neighboring sites. This estimate is higher than previous estimates for this population: $2.06 \mathrm{yr}$ (Girondot \& Fretey 1996) and $2.25 \mathrm{yr}$ (Chevalier \& Girondot 1998). However, these previous estimates (without CIs) were simply based on observed numbers of marked females and biased by death over time, tag loss and time series truncation. We calculated a remigration interval corrected for survival by sampling the proportions of females coming back after 2, 3, 4, 5 and $>6$ yr (the latter forced to 6 ) from Dutton et al.'s Fig. 2 (respectively 0.47, 0.30, 0.16, 0.04 and 0.02 ). The resulting mean 2.828 is close to our estimate. A similar estimate $(2.7 \pm 1.0 \mathrm{yr})$ was also obtained in a Florida population increasing at $10 \%$ $\mathrm{yr}^{-1}$ (Stewart et al. 2014).

Accounting for survival, this interval translates into an average number of $1.704 \pm 0.035$ further reproductive seasons for an adult female leatherback. This is remarkably low for a long-lived species with a high average age at maturity, generally recognized to be around 12 to $14 \mathrm{yr}$, although extremely variable (Chevallier et al. in press). The large offspring number produced by nesting season is another component of a particular demographic strategy. In homeother- 
mic vertebrates, for which much more demographic information is available, all species having interbirth intervals higher than $1 \mathrm{yr}$ and high age at first reproduction (elephants, cetaceans, albatrosses) have only 1 young at a time, together with an adult annual survival probability higher than 0.95 in the absence of anthropogenic impacts (Gaillard et al. 1989). The low number of reproductive seasons brings leatherbacks closer to semelparity than other long-lived vertebrates. As temporary emigration, in particular temporary movement to lay eggs in Suriname, may induce some underestimation of the number of reproductive seasons, it would be extremely useful in the future to share CMR data for extended analyses.

The amount of data available to us made it possible to demonstrate a significant variation over time in the 3 key demographic parameters considered: annual survival, probability of departing after a laying season and probability of returning. A priority will be to search for environmental correlates of this variation, although our demographic parameter estimates are based on a mix of individuals at sea and close to shore, and with different lengths of time since their last reproductive season. Links with local covariates such as indicators of beach erosion and with fishing and oceanographic covariates such as the North Atlantic Oscillation index have to be investigated, with the hope of being able to project demographic results based on climate models (Gauthier et al. 2016). The choice of such covariates will benefit from the knowledge of the geographical trajectories of individuals marked with satellite transmitters (Fossette et al. 2010, Galli et al. 2012, Baudouin et al. 2015, Chambault et al. 2015, 2016a,b, 2017, 2018, Treasure et al. 2017, Nivière et al. 2018).

Finally, the structure provided here for departure, return, intermittent reproduction and mark loss could be used in broader and richer analyses. One could in particular take advantage of the within-season recaptures to decipher the trade-offs between transience and mark loss. This would be equivalent to some kind of robust or quasi-robust design to extract as much biological information as possible from marked individuals, an invaluable source of information in all animal populations, in particular those such as the leatherback in which only a small segment of the population is accessible to sampling in an intermittent fashion.

A combination of CMR and other models for the analysis of demographic data, genetics and genomic information, telemetry data and oceanic data can be used to estimate demographic parameters in marine turtles, such as survival, recruitment, dispersion, bycatch and population growth rates. We would then be able to quantify the relative effects of biotic and abiotic factors (e.g. habitat type, disease, climate, competition, predation) along with individual covariates (e.g. size, weight, age, social status, nesting success, reproductive effort) on these demographic parameters. These estimates will make it possible to feed population matrix models and individual-based models for long-term population projections. In fine, analyses of population viability will make it possible to predict the demographic effects of resource exploitation, modulated by processes such as resource availability, predation and weather. Use of these complementary models will improve the definition of units of conservation and management, and the evaluation of the potential for such threatened populations to respond to changing environments in the context of global change.

Acknowledgements. This study was carried out within the framework of the Plan National d'Actions Tortues Marines en Guyane (National Action Plan for Guiana Sea Turtles) and was produced as part of the CARET2 cooperation project between French Guiana and Suriname, headed by the French Guiana office of WWF France, in partnership with Kwata NGO, the French National Agency for Game and Wildlife (ONCFS), the French Guiana Regional Nature Park (PNRG) and WWF Guianas. The authors also appreciate the support of the ANTIDOT project (Pépinière Interdisciplinaire Guyane, Mission pour l'Interdisciplinarité, CNRS), the French Guiana Regional Council, the EDF Foundation and Fondation de France. Hélène Delvaux (DEAL Guyane/ MNBSP/BD) is thanked for her constant support with financial facilities. The authors thank the organizations that contributed to the collective database of marine turtles in French Guiana (DEAL Guyane française, ESE, CNRS-IPHC, Kwata, ONCFS, SEPANGUY, RNA, WWF, Kulalasi). We also thank 2 anonymous referees for their thorough and helpful comments.

\section{LITERATURE CITED}

Baudouin M, de Thoisy B, Chambault P, Berzins R and others (2015) Identification of key marine areas for conservation based on satellite tracking of post-nesting migrating green turtles (Chelonia mydas). Biol Conserv 184: 36-41

Carr A, Carr MH (1972) Site fixity in the Caribbean green turtle. Ecology 53:425-429

Chaloupka M, Kamezaki N, Limpus C (2008) Is climate change affecting the population dynamics of the endangered Pacific loggerhead sea turtle? J Exp Mar Biol Ecol 356:136-143

Chambault P, Pinaud D, Vantrepotte V, Kelle L and others (2015) Dispersal and diving adjustments of the green turtle Chelonia mydas in response to dynamic environmental conditions during post-nesting migration. PLOS ONE 10:e0137340 
Chambault P, de Thoisy B, Heerah K, Conchon A and others (2016a) The influence of oceanographic features on the foraging behavior of the olive ridley sea turtle Lepidochelys olivacea along the Guiana coast. Prog Oceanogr 142:58-71

Chambault P, de Thoisy B, Kelle L, Berzins R and others (2016b) Inter-nesting behavioural adjustments of green turtles to an estuarine habitat in French Guiana. Mar Ecol Prog Ser 555:235-248

Chambault P, Roquet F, Benhamou S, de Thoisy B and others (2017) The Gulf Stream frontal system: a key oceanographic feature in the habitat selection of the leatherback turtle? Deep Sea Res I 123:35-47

* Chambault P, de Thoisy B, Huguin M, Martin J and others (2018) Connecting paths between juvenile and adult habitats in the Atlantic green turtle using genetics and satellite tracking. Ecol Evol 8:12790-12802

Chevalier J, Girondot M (1998) Dynamique de pontes des tortues luths en Guyane française durant la saison 1997. Bull Soc Herpétol Fr 85-86:5-19

Chevalier J, Cazelles B, Girondot M (1998) Apports scientifiques à la stratégie de conservation des tortues luths en Guyane française. J Agric Tradit Bot Appl Rev Ethnobiol 40:485-507

Chevallier D, Mourrain B, Girondot M (in press) Modelling leatherback biphasic indeterminate growth using a modified Gompertz equation. Ecol Modell

Choquet R, Rouan L, Pradel R (2009a) E-SURGE: a software application for fitting multievent models. In: Thomson DL, Cooch EG, Conroy MJ (eds) Modeling demographic processes in marked populations. Springer, New York, NY

Choquet R, Lebreton JD, Gimenez O, Reboulet AM, Pradel $\mathrm{R}$ (2009b) U-CARE: utilities for performing goodness of fit tests and manipulating CApture-REcapture data. Ecography 32:1071-1074

Clutton-Brock T, Sheldon BC (2010) Individuals and populations: the role of long-term, individual-based studies of animals in ecology and evolutionary biology. Trends Ecol Evol 25:562-573

Dutton DL, Dutton PH, Chaloupka M, Boulon RH (2005) Increase of a Caribbean leatherback turtle Dermochelys coriacea nesting population linked to long-term nest protection. Biol Conserv 126:186-194

Ferraroli S, Georges JY, Gaspar P, Le Maho Y (2004) Endangered species: where leatherback turtles meet fisheries. Nature 429:521-522

Fletcher D, Lebreton JD, Marescot L, Schaub M, Gimenez O, Dawson S, Slooten E (2012) Bias in estimation of adult survival and asymptotic population growth rate caused by undetected capture heterogeneity. Methods Ecol Evol 3:206-216

Fossette S, Kelle L, Girondot M, Goverse E and others (2008) The world's largest leatherback rookeries: a review of conservation-oriented research in French Guiana/Suriname and Gabon. J Exp Mar Biol Ecol 356:69-82

Fossette S, Girard C, Lopez-Mendilaharsu M, Miller P and others (2010) Atlantic leatherback migratory paths and temporary residence areas. PLOS ONE 5:e13908

Fretey J, Lescure J (1998) Les tortues marines en Guyane française: bilan de vingt ans de recherche et de conservation. J Agric Tradit Bot Appl Rev Ethnobiol 40:219-238

* Gaillard JM, Pontier D, Allaine D, Lebreton JD, Trouvilliez J, Clobert J (1989) An analysis of demographic tactics in birds and mammals. Oikos 56:59-76

Gaillard JM, Lemaître JF, Berger V, Bonenfant C and others (2016) Life histories, axes of variation in. In: Kliman RM (ed) Encyclopedia of evolutionary biology, Vol 2. Academic Press, Oxford, p 312-323

*Galli S, Gaspar P, Fossette S, Calmettes B, Hays GC, Lutjeharms JRE, Luschi P (2012) Orientation of migrating leatherback turtles in relation to ocean currents. Anim Behav 84:1491-1500

*Gauthier G, Péron G, Lebreton JD, Grenier P, van Oudenhove L (2016) Partitioning prediction uncertainty in climate-dependent population models. Proc Biol Sci 283: 20162353

Gibbons JW, Andrews KM (2004) PIT tagging: simple technology at its best. Bioscience 54:447-454

KGimenez O, Lebreton JD, Gaillard JM, Choquet R, Pradel R (2012) Estimating demographic parameters using hidden process dynamic models. Theor Popul Biol 82:307-316

Girondot M, Fretey J (1996) Leatherback turtles, Dermochelys coriacea, nesting in French Guiana, 1978-1995. Chelonian Conserv Biol 2:204-208

Gould WR, Nichols JD (1998) Estimation of temporal variability of survival in animal populations. Ecology 79: 2531-2538

*Hallett TB, Coulson T, Pilkington JG, Clutton-Brock TH, Pemberton JM, Grenfell BT (2004) Why large-scale climate indices seem to predict ecological processes better than local weather. Nature 430:71-75

Hawkes LA, Broderick AC, Godfrey MH, Godley BJ (2007) Investigating the potential impacts of climate change on a marine turtle population. Glob Change Biol 13:923-932

* Hilterman ML, Goverse E (2007) Nesting and nest success of the leatherback turtle (Dermochelys coriacea) in Suriname, 1999-2005. Chelonian Conserv Biol 6:87-100

IUCN (2009) Leatherback turtles and climate change. In: The IUCN Red List of Threatened Species, www.iucn.org/ sites/dev/files/import/downloads/fact_sheet_red_list_turtle _v2.pdf (accessed December 2017)

Janzen FJ (1994) Climate-change and temperature dependent sex determination in reptiles. Proc Natl Acad Sci USA 91:7487-7490

*Kelle L, Gratiot N, Nolibos I, Thérèse J, Wongsopawiro R, De Thoisy B (2007) Monitoring of nesting leatherback turtles (Dermochelys coriacea): contribution of remote sensing for real-time assessment of beach coverage in French Guiana. Chelonian Conserv Biol 6:142-149

Kendall WL, Nichols JD, Hines JE (1997) Estimating temporary emigration using capture-recapture data with Pollock's robust design. Ecology 78:563-578

Lebreton JD, Burnham KP, Clobert J, Anderson DR (1992) Modeling survival and testing biological hypotheses using marked animals: a unified approach with case studies. Ecol Monogr 62:67-118

K Lebreton JD, Hines JE, Pradel R, Nichols JD, Spendelow JA (2003) Estimation by capture-recapture of recruitment and dispersal over several sites. Oikos 101:253-264

Lebreton JD, Nichols JD, Barker RJ, Pradel R, Spendelow JA (2009) Modeling individual animal histories with multistate capture-recapture models. Adv Ecol Res 42:88-173

* Lovich JE, Ennen JR, Agha M, Gibbons JW (2018) Where have all the turtles gone, and why does it matter? Bioscience 68:771-781

Lutz PL, Musick JA, Wyneken J (eds) (2003) The biology of sea turtles, Vol 2. CRC Press, Boca Raton, FL

*McMahon CR, Hays GC (2006) Thermal niche, large-scale movements and implications of climate change for a critically endangered marine vertebrate. Glob Change Biol 12:1330-1338 
Molfetti E, Torres Vilaça S, Georges JY, Plot V and others (2013) Recent demographic history and present fine-scale structure in the northwest Atlantic leatherback (Dermochelys coriacea) turtle population. PLOS ONE 8:e58061

Nivière M, Chambault P, Perez $T$, Etienne D and others (2018) Identification of marine key areas across the Caribbean to ensure the conservation of the critically endangered hawksbill turtle. Biol Conserv 223:170-180

Pfaller JB, Chaloupka M, Bolten AB, Bjorndal KA (2018) Phylogeny, biogeography and methodology: a metaanalytic perspective on heterogeneity in adult marine turtle survival rates. Sci Rep 8:5852

Pfaller JB, Williams KL, Frick MG, Shamblin BM, Nairn CJ, Girondot M (2019) Genetic determination of tag loss dynamics in nesting loggerhead turtles: a new chapter in 'the tag loss problem'. Mar Biol 166:97

* Pilcher N, Chaloupka M (2013) Using community-based monitoring to estimate demographic parameters for a remote nesting population of the Critically Endangered leatherback turtle. Endang Species Res 20:49-57

Pradel R (2005) Multievent: an extension of multistate capturerecapture models to uncertain states. Biometrics 61:442-447

Pradel R, Hines JE, Lebreton JD, Nichols JD (1997) Capturerecapture models taking account of transients. Biometrics 53:60-72

Rivalan P, Godfrey MH, Prévot-Julliard AC, Girondot M (2005a) Maximum likelihood estimates of tag loss in leatherback sea turtles. J Wildl Manag 69:540-548

Rivalan P, Prévot-Julliard AC, Choquet R, Pradel R, Jacquemin B, Girondot M (2005b) Trade-off between current reproductive effort and delay to next reproduction in the leatherback sea turtle. Oecologia 145:564-574

Rivalan P, Dutton PH, Baudry E, Roden SE, Girondot M (2006a) Demographic scenario inferred from genetic data in leatherback turtles nesting in French Guiana and Suriname. Biol Conserv 130:1-9

Rivalan P, Pradel R, Choquet R, Girondot M, Prévot-Julliard AC (2006b) Estimating clutch frequency in the sea turtle Dermochelys coriacea using stopover duration. Mar Ecol Prog Ser 317:285-295

Rivalan P, Prévot-Julliard AC, Girondot M (2008) First estimation of the annual female survival rate based on tagging data from French Guiana. NOAA Tech Memo NMFS-SEFSC-567

Sarti Martinez A (2000) Dermochelys coriacea. The IUCN Red List of Threatened Species 2000: e.T6494A12784317 (accessed December 2017)

Editorial responsibility: Clive McMahon,

Hobart, Tasmania, Australia
Seebacher F, Franklin CE (2005) Physiological mechanisms of thermoregulation in reptiles: a review. J Comp Physiol B 175:533-541

Seminoff JA (2004) Sea turtles, red listing, and the need for regional assessments. Mar Turtle Newsl 106:4-6

Seminoff JA, Shanker K (2008) Marine turtles and IUCN red listing: a review of the process, the pitfalls, and novel assessment approaches. J Exp Mar Biol Ecol 356: $52-68$

Spotila JR, Leslie AJ, Paladino FV (1996) Population cycles or population decline: Are leatherback turtles going extinct? In: Keinath JA, Barnard DE, Musick JA, Bell BA (eds) Proc 15th Ann Workshop on Sea Turtle Biology and Conservation. NOAA Tech Memo, NMFS-SEFSC387, p 308

Spotila JR, Reina RD, Steyermark AC, Plotkin PT, Paladino FV (2000) Pacific leatherback turtles face extinction. Nature 405:529-530

Stewart KR, Martin KJ, Johnson C, Desjardin N, Eckert SA, Crowder LB (2014) Increased nesting, good survival and variable site fidelity for leatherback turtles in Florida, USA. Biol Conserv 176:117-125

* Swihart RK, Dunning JBJ, Waser PM (2002) Gray matters in ecology: dynamics of pattern, process and scientific progress. Bull Ecol Soc Am 83:149-155

* The Northwest Atlantic Leatherback Working Group (2019) Dermochelys coriacea (Northwest Atlantic Ocean subpopulation).The IUCN Red List of Threatened Species 2019:e.T46967827A83327767. http://dx.doi.org/ 10.2305/IUCN.UK.2019-2.RLTS.T46967827A83327767.en (accessed November 2019)

Thorson JT, Punt AE, Nel R (2012) Evaluating population recovery for sea turtles under nesting beach protection while accounting for nesting behaviours and changes in availability. J Appl Ecol 49:601-610

Tomillo MPS (2007) Factors affecting population dynamics of eastern Pacific leatherback turtles (Dermochelys coriacea). PhD thesis, Drexel University, Philadelphia, PA

*Treasure AM, Roquet F, Ansorge IJ, Bester MN and others (2017) Marine mammals exploring the oceans pole to pole: a review of the MEOP consortium. Oceanography (Wash DC) 30:132-138

Wallace B (2019) Northwest Atlantic leatherback nesting trend analyses. WIDECAST annual general meeting, Paramaribo, Suriname, 19-21 Mar 2019. Wider Caribbean Sea Turtle Conservation Network

Submitted: May 27, 2019; Accepted: November 25, 2019

Proofs received from author(s): January 27, 2020 